\section{rev Psi}

Revista de Psicología (UNLP)

https://revistas.unlp.edu.ar/revpsi

\title{
Encuentros posibles con el autismo
}

\section{Luz Elena Gaviria-Vélez ${ }^{1,2}$}

\section{Correspondencia}

luzegaviria@gmail.com

\section{Filiaciones institucionales}

${ }^{1}$ Nueva Escuela Lacaniana (NEL, Medellín, $\quad \quad 2$ Asociación Mundial de Psicoanálisis (AMP)

\section{Resumen}

Uno de los elementos que interrogan la práctica analítica es la oposición entre sentido y goce; esto renueva la pregunta de: ¿cómo hacer posible el encuentro con el autista que está desconectado del Otro y del propio cuerpo? Pregunta que conviene inscribir en la orientación lacaniana y, particularmente, en la práctica con niños autistas.

La posición del analista que le concierne es disponerse a leer el síntoma en cada autista para introducirse en la lectura de su subjetividad, en el padecimiento que lo habita, y leer la manifestación de su defensa para no entrar en el juego discursivo.

Hago uso de una viñeta de mi práctica clínica con la que me propongo examinar ¿que sería una intervención contando con la singularidad del cuerpo del autista?

\section{Palabras clave}

autismo | defensa | Un-cuerpo | acontecimiento de cuerpo

\section{Cómo citar}

Gaviria-Vélez, L. E. (2021). Autismo y psicoanálisis. Una apuesta del lado de la vida. Revista de Psicología, 20(1), 63-69. HTTPS://DX.DOI. ORG/10.24215/2422572XE117

\section{Proceso editorial}

Recibido

26 feb. 2021

Aceptado

12 jun. 2021
1 ra decisión

12 abr. 2021

Publicado

31 jul. 2021
Coordinadora del dossier

María Cristina Piro (Facultad de Psicología UNLP, Argentina).
ISSN

2422-572X

\section{Licencia}

Licencia de Cultura Libre CC-BY 4.0

(Compartir - Adaptar - Atribuir)

RevPsi es una publicación de la

Facultad de Psicología (Universidad

Nacional de La Plata, Argentina) 


\section{Possíveis encontros com o autismo}

\section{Resumo}

Um dos elementos que questiona a prática analítica é a oposição entre sentido e gozo; isto renova a questão de como tornar possível o encontro com o autista, que está desligado do Outro e do seu próprio corpo. É uma questão que deve ser inscrita na orientação lacaniana e particularmente na prática com crianças autistas. A posição do analista é estar pronto a ler o sintoma em cada pessoa autista, para entrar na leitura da sua subjetividade, no sofrimento que o habita, e na manifestação da sua defesa, a fim de não entrar no jogo discursivo.

Utilizo uma vinheta da minha prática clínica com a qual pretendo examinar o que seria uma intervenção tendo em conta a singularidade do corpo do autista?

\section{Palavras-chave}

autismo | defesa | Un-corpo | acontecimento corporal

\section{Possible encounters with autism}

\section{Abstract}

One of the elements that question analytic practice is the opposition between meaning and jouissance. This renews the question: how to make possible the encounter with the autistic person who is disconnected from the Other and from his or her own body? This question is to be inscribed in the Lacanian orientation and, in particular, in the practice with autistic children. The position of the analyst concerned is to be ready to read the symptom in each autistic person in order to enter into the reading of his subjectivity, into the suffering that inhabits him, and to read the manifestation of his defence in order not to enter into the discursive game. I use a clinical vignette with which I intend to examine: what would be an intervention taking into account the singularity of the autistic's body?

\section{Keywords}

autism | defense | A-body | body affection 


\section{Aspectos destacados del trabajo}

- El analista ha de saber leer la subjetividad del sujeto autista.

- Es necesario que el analista aporte su cuerpo para propiciar la posibilidad de hacerse a un cuerpo el autista.

- Es posible la relación con el autista y establecer un lazo sutil.

- La experiencia clínica nos enseña cómo el autista propicia ampliar su mundo al hacer de otra manera con su Uno de goce que itera.

El encuentro con el autista es inolvidable en muchos sentidos, resalto uno de ellos y es su efecto con relación a lo que aporta a la formación del analista por incidir en la manera en que ha de orientarse para lograr adentrarse en la soledad que habita el autista como ser hablante.

El psicoanálisis de orientación lacaniana considera que el autismo es una afectación que involucra al cuerpo y el lenguaje y determina un disfuncionamiento entre cuerpo y lenguaje. En consecuencia, esta dificultad hace que sea muy difícil entrar en el lazo social. Hay que tener en cuenta que para los autistas el cuerpo no está organizado como en los neuróticos. No tienen el sentimiento de una unidad corporal; tienen el sentimiento extraño del cuerpo.

La afirmación de Lacan: "basta tener un cuerpo para gozar un cuerpo vivo" (Lacan, 1972-1973/2007) para sentirlo como propio, manipularlo y apropiárselo, es un proceso que compara J. A. Miller con el proceso de las comidas. Es decir, nombra en el viviente un primer momento cero con relación al "goce crudo del viviente" (Miller, 2008) y un segundo momento surgiría lo cocido ante el impacto de lalengua sobre el cuerpo vivo como golpe que deja huella y causa una afectación del cuerpo, que precipita a responder con una defensa que fija un goce Uno, el cual J. A. Miller llama "goce cocido", que hace referencia de la presencia de un real del lado del signo que itera en el cuerpo y con el cual ha de arreglárselas todo ser hablante.

En este sentido, el analista ha de leer el síntoma autístico para todo ser hablante, como respuesta al golpe en el cuerpo del encuentro con lalengua, por el hecho de estar vivo y tener un cuerpo que se goza, sin que el sujeto lo sepa. Ahora bien, este goce Uno que se instaura e itera en cada ser hablante ha de encontrar su forma singular de arreglárselas ya que concierne a todo ser hablante construir su defensa ante el encuentro con el "hay de lo Uno del goce y es un acontecimiento de cuerpo" (Miller, 2011, p. 220). "Un cuerpo que se convierte entonces en hablaser" (parletre) (Miller, 2011, p. 108).

La clínica del autismo nos enseña cómo frente que a ese impacto de lalengua, que es un "acontecimiento de cuerpo que acompaña a la intrusión del sujeto en el campo 
del lenguaje" (Laurent, 2013, p. 107), el autista no toma el recurso al Otro simbólico para su defensa y esta condición de desconectado del Otro del significante lo deja atrapado en afectos indefinibles, pero sobre todo sin recursos para separarse de un exceso de excitación que invade el cuerpo. Ese goce Uno, que no se borra, podríamos decir que sigue estando presente con la forma de goce crudo, no es un cuerpo que cuenta con recursos imaginarios y simbólicos, por consiguiente, es un cuerpo sin afectación del frío, del calor, un cuerpo que se golpea y que no sufre, un cuerpo que no logra identificarse a sí mismo. Hay una sensibilidad al demasiado ruido de la lengua y toda palabra puede producir terror por tratar el ruido de la lengua por fuera del sentido, es pura sonoridad desorganizada con lo cual tiene que arreglárselas, es una experiencia primera de goce en el cuerpo.

Orientarse por los aportes de las enseñanzas de Lacan y J. A. Miller para el encuentro con la clínica del autismo y su práctica hacen posible el lazo con el autista y puede darse que se amplíe su mundo e invente otras formas de defensa ante la invasión de ese goce feroz que lo invade. Retomaré trozos de una viñeta clínica para ilustrar cómo se verifican los conceptos y sus enseñanzas para el practicante.

Cuando ingresa Sara al consultorio, de inmediato su cuerpo manifiesta respuestas tales como cerrar los ojos, taparse los oídos, intentar caminar por el lugar con un ojo medio abierto y luego se sienta en un rincón un rincón en silencio sin hacer uso de la mirada. Transcurren meses del encuentro con este mismo circuito, acompañada de la posición del analista en silencio como un objeto más del lugar. En otro tramo de los encuentros, abre los ojos y mira los zapatos del analista, se dirige a ellos y se los quita y se los coloca ella misma. Momento significativo que marca un viraje del encuentro, ya que Sara, en consecuencia, como efecto de meterse en los zapatos de Luz Elena, de quitárselos al analista y de que le falta algo, produce en ese vaciamiento una afectación de orden satisfactorio en el cuerpo de Sara, que le permite abrir los ojos y caminar por el espacio tranquila.

Como psicoanalista nombro con tono de canto lo acontecido en el encuentro: "Sara camina con los zapatos de Luz Elena". Al ver que soporta la voz con tono de canto, la introduzco, además, en nuestros sucesivos encuentros para acompañar lo acontecido en el espacio de intercambio con Sara.

Transcurren dos años en el mismo circuito repetitivo, hasta que un día Sara hace uso de la voz de ella, repitiendo lo que Luz Elena cantaba por meses con el mismo tono de voz. Este tomar las palabras de Luz Elena señala otro encuentro posible entre Sara y Luz Elena que, igualmente, puede nombrarse como afectación del cuerpo, de ese Un-cuerpo que lo vive satisfactoriamente y le permite hacer uso del objeto voz copiado de cómo lo nombra Luz Elena.

Luego de seis años de encuentros, donde el analista aloja las invenciones de Sara, se abre para ella la posibilidad de ampliar su mundo solitario y hacer lazo con los otros, sin taparse los ojos y los oídos. En los encuentros iniciales con Sara, se suscitaron muchas preguntas, más que respuestas. Una de ellas es ¿Cómo hacer posible ese encuentro contando con la singularidad de ese cuerpo que habita el autista, el cual 
presenta una consistencia de cuerpo que no ha sido ordenado por los significantes del Otro del cual esta desconectado al punto de no entrar en el juego discursivo?

La posición del analista que conviene es disponerse a leer el síntoma en cada autista para introducirse en la lectura de su subjetividad, en el padecimiento que lo habita y en su medio singular de protección. "Es decir, leer su relación al cuerpo, al saber, a los objetos, al Otro de la palabra y del lenguaje, para poder establecer de qué se protege ese sujeto, con qué estatuto del cuerpo y de los objetos cuenta, con qué no se las puede arreglar" (Lijtinstens, 2020).

La viñeta ilustra la intervención de la analista orientada por la propuesta de direccionar la operación analítica en el encuentro con el autista teniendo en cuenta el cuerpo del autista como alguien que no se ubica "del lado de los cuerpos atrapados por el discurso" (Lacan, 2012, p. 217). Esto no quiere decir que no haya un cuerpo, lo hay testimonio de Un goce, un gozarse que es previo a la constitución imaginaria y simbólica del mismo. Previo a cualquier tratamiento del Otro que supone un pasaje del Uno del cuerpo al Otro del lenguaje como aparato de acceso al goce del propio cuerpo. Aun así, se corrobora que no es ajeno a las resonancias de la lalengua sobre el cuerpo, en el detalle clínico de hablar y tomar la voz como habla Luz Elena, lo cual, podríamos decir, se ha establecido una satisfacción en el cuerpo que abre la posibilidad de un cifrado de goce en donde se cede algo del objeto voz y mirada en esa zona de intercambio con el cuerpo del analista.

Además, se puede observar con la viñeta cómo el tratamiento repetitivo de ese goce Uno que itera y se manifiesta en las respuestas de taparse los ojos, los oídos y aislarse en un rincón, en el encuentro con el analista que pone en juego su cuerpo al sacar de la escena el cuerpo que le dirige la mirada, la voz, se saca los zapatos, es decir, se descompleta, puede abrirse Sara a un Otro menos feroz e instaurar un lazo que vaya en contra del propio síntoma autista que el sujeto usa para defenderse de un real intratable e invasivo. Encuentro posible, "lazo sutil" (Tendarlz, 2012), que amplía su mundo solitario y logra efectos en el lazo social, al encontrar la posibilidad de inventar otra manera de defenderse de la exigencia de un goce devastador.

Otra enseñanza que deja la viñeta es la del lugar que conviene al analista en ese encuentro, como un mueble más del entorno, sabiendo el analista que no es un objeto cualquiera, porque, como lo enseña la viñeta, su presencia moviliza las defensas del sujeto: cede al tomar del analista los zapatos y con este objeto se hace evidente el uso de este objeto analista.

Cuando el analista consigue hacerse aceptar, mediante una aproximación no intrusiva, el autista pone en juego una defensa diferente frente al goce invasivo $y$ hace de ese lugar del analista el punto desde donde emanan iniciativas que hay que apoyar; se hace uso de ese otro cuerpo como si se tratase de una extensión del suyo propio. Sara se abre al Otro a través del objeto analista.

En consecuencia, Sara ya no pasa sus días y sus noches tapándose los oídos y cerrando los ojos para protegerse de la intrusión invasiva del Otro feroz, ya que, a partir de 
ese encuentro, de ese aparejamiento con el analista como objeto y los zapatos, se instaura un nuevo Otro donde los intercambios son posibles.

Esta orientación, de leer el síntoma de cada autista como solución que ha encontrado para tratar su padecimiento, implica tener en cuenta su respuesta sintomática, que, aunque se la vea precaria, es la vía por donde luego es posible con la presencia del analista transformarse en otro síntoma que le permita acceder a un lazo social y a otra relación con el cuerpo, es decir, a vivir con menos sufrimiento y acceder a otro tipo de solución con su existencia.

Para el tratamiento del padecimiento del autista, se cuenta con el cuerpo del autista, "no el cuerpo constituido en relación al Otro sino, como suele decirse, el cuerpo propio, el Un-cuerpo" (Miller, 2013, p. 107), que entra a jugar la partida con el cuerpo del analista. Partida que es posible jugarse no sin el cuerpo del analista puesto allí en la escena, como lo ilustra Sara, toma el cuerpo del analista, le saca los zapatos, la voz también, lo que provoca la construcción de un Otro que le posibilita habitar el cuerpo y su mundo con una nueva invención que se construye a partir de ese encuentro.

Comprender de qué se trata esta orientación hace posible acompañar la soledad de un niño autista y existir de una manera no invasiva para el autista sin que tenga la imperiosa necesidad de defenderse, lo cual traza la vía de un posible lazo con el autista de un diálogo por fuera de la significación, que toma otra vía y es la respuesta a una presencia a la que puede consentir. Diálogo que no apunta a la comunicación, sino a la interlocución vacía de sentido.

Orientación que se basa en las elucidaciones de Lacan cuando introduce en la concepción del cuerpo, además de la consistencia simbólica, la existencia de un elemento mínimo, la "consistencia imaginaria" (Miller, 2013, p. 417) en el ser hablante, previa a la inscripción discursiva, lo cual señala un pasaje importante en su enseñanza, en donde se pasa del Uno del significante al Uno del cuerpo.

Se despeja como consistencia primera del ser hablante el cuerpo, no el sujeto del significante. El cuerpo es la única consistencia del ser hablante, es lo que lo mantiene unido. Señala Lacan, en el Seminario El sinthome, que esa consistencia es imaginaria, sin duda, pero esa consistencia se basa en una relación del ser hablante que mantiene con su cuerpo, no con el significante. Lacan, entonces, aísla como primaria la relación corporal, la relación del ser hablante con su cuerpo propio donde está implicado lo imaginario y luego establece la distinción entre esa relación primaria y la relación con el cuerpo otro, en la que hay pensamiento, sentido y referencia a la relación sexual.

El cuerpo del analista como soporte del encuentro con el cuerpo de Sara produce estos diversos movimientos que hay que tomar como una extracción de goce a la cual consiente Sara, “... el sujeto llega a ceder algo de la carga de goce que afecta a su cuerpo y ello sin que tal cesión de goce le sea en exceso insoportable” (Laurent, 2013, p. 85).

El momento en que Sara encarna la voz con la mediación de la ecolalia, de hablar como lo dice luz Elena, ilustra el modo de afectación en el cuerpo de pasar del silencio a una especie de satisfacción en el cuerpo sin terror de modular con una voz que ella 
podía soportar, de ahí pasa a armar otras cadenas significantes, introduciendo las palabras, lo cual ilustra "el cuerpo que se olvida en el decir" (Laurent, 2013, p. 115).

En consecuencia, su modo de tratamiento del Otro se ha modificado un poco, por el encuentro con el cuerpo del analista, debido a que este cuerpo se presenta como alguien sin zapatos, con algo que falta, barrado. La pérdida de goce se produce, pues, por una satisfacción vinculada al encuentro con el analista en esa posición pasiva, pero a la vez causante de la posibilidad de invención de ese Otro que le abre otras posibilidades de afectación en el cuerpo.

Este encuentro posible para el analista con el síntoma autístico de Sara como ser hablante abre la posibilidad de ilustrar y tratar de comprender la enseñanza de Lacan a la altura del Seminario 24 de estar orientado por el goce sin sentido, es decir, el efecto en el cuerpo, lo que conduce a leer el rastro de lo real, más que los significados. Dice Lacan: "no es a su conciencia a lo que el sujeto está condenado, sino a su cuerpo" (Lacan, 1977, p. 32), de ahí que reciba de un "psicoanalista lo que molesta su defensa".

Es decir, que para todo ser hablante es posible en el encuentro con un analista ir en contra del propio síntoma autista, con el que se defiende de un real, del hay de lo Uno del goce y es un acontecimiento del cuerpo. Pero no alcanza con el deseo del analista como "pureza", es necesario que el analista "aporte su cuerpo, a través del tono, de la voz, el acento y hasta el gesto o la mirada" (Miller, 2013). Encuentro que, contando con el lazo y el lugar o posición del analista, conduce, luego de un nueva satisfacción corporal conduce a hacer de su vida una obra de arte.

\section{Referencias}

Lacan, J. (1972-1973/2007). Seminario 20. Aun (D. Rabinovich, trad.). Paidós.

Lacan, J. (1977). Seminario 24. L'insu que sait de l'une-bevue s'áile a mouree. Clase 11-1-77. (Traducido por la Escuela Freudiana de Buenos Aires). Inédito.

Lacan, J. (2012) . Seminario 19 ... o peor (G, Arenas, trad.). Paidós.

Laurent, E. (2013). La batalla del autismo (E. Berenguer, trad.). Grama.

Lijtinstens, C. (2020). El cuerpo y los objetos. Observatorio de políticas de autismo. [Conferencia inédita].

Miller, J-A. (1997-1998/2008). Partenaire-síntoma. Los cursos psicoanalíticos de Jacques-Alain Miller (D. G. Saroka, trad.). Paidós.

Miller, J-A. (2011). El ser y el Uno. Inédito.
Miller, J-A. (2006-2007/2014). El ultimísimo Lacan. Los cursos psicoanalíticos de Jacques-Alain Miller (S. Verley, trad.). Paidós.

Miller, J-A. (2004-2005/2013). Piezas sueltas (G. Arenas, trad.). Paidós.

Miller, J-A. (2000-2001/2013). El lugar y el lazo. Los cursos psicoanalíticos de Jacques-Alain Miller (G. Arenas, trad.), Paidós.

Tendlarz, S. E. (octubre de 2012). Lazo sutil con el autista [presentación en jornadas]. Jornadas sobre Autismo de la Escuela de la Causa Freudiana, París. HTTP://WWW.SILVIAELENATENDLARZ. COM/INDEX.PHP?FILE=ARTICULOS/AUTISMO/ELLAZO-SUTIL-CON-EL-AUTISTA.HTML 